\title{
A Simple Cost Reduction Strategy for Small Liquidity Traders: Trade at the Opening
}

\author{
Raymond M. Brooks and Tie Su*
}

\begin{abstract}
We extend the market microstructure literature by examining trading strategies of a small discretionary liquidity trader in call and continuous markets. Our investigation of trading strategies uses intraday market and limit orders, and introduces the market-at-open order as an alternative strategy for a small liquidity trader. We find that a small trader can reduce transaction costs by trading at the opening. Using tick-by-tick transaction data, we demonstrate that the market-at-open order consistently produces better prices than market and limit orders executed during the trading day.
\end{abstract}

\section{Introduction}

Traders have an economic incentive to act strategically. In this study, we examine three types of submission strategies for small liquidity traders: the marketat-open order, intraday market orders, and intraday limit orders. Our objective is to determine if any particular strategy consistently outperforms the other strategies in receiving better prices for a small discretionary liquidity trader. We use tickby-tick transaction data to simulate order executions. Our results demonstrate that the market-at-open strategy benefits a small liquidity trader. We contribute to the existing literature in that we empirically contrast trading strategies in a continuous market and a call market and provide empirical support for the theoretical trading models that show liquidity traders have a preference to band together when submitting orders to trade.

The first set of strategic trading models concentrates on the optimal trading behavior of informed traders. For example, Kyle (1985) looks at a sequential batchtrading market in which informed traders and liquidity traders submit orders to a risk-neutral market maker. Attention is paid to the strategic trading patterns of

\footnotetext{
*Department of Accounting, Finance, and Information Management, Oregon State University, Corvallis, OR 97331-2603, and Department of Finance, University of Miami, Coral Gables, FL 331246552 , respectively. This paper benefited from the comments of Kerry Back, Matthew Billett, Charles Corrado, Pat Fishe, Tina Galloway, Bradford Jordan, David Mauer, and Susan Monaco. The authors thank Ron Howren for excellent research assistance. The authors also acknowledge financial support from the Financial Research Institute at the University of Missouri-Columbia. Special thanks to Jon Karpoff (the editor) and Joel Hasbrouck (the referee) for detailed comments and helpful suggestions. We alone are responsible for any errors and omissions.
} 
informed traders and their optimal trading pattern with long-lived information. The liquidity trader is a noise trader in this model and does not act strategically. The non-strategic behavior of the liquidity trader is an important restriction but also introduces an interesting question: Is there an optimal trading strategy for a liquidity trader?

In a variant of the Kyle model, Admati and Pfleiderer (1988) introduce a discretionary trader. In their model, a second type of uninformed trader is added to the mix: a trader who has discretion to submit trades throughout the day. Admati and Pfleiderer find it optimal for discretionary traders to submit trades simultaneously with other liquidity traders. O'Hara (1994) provides the following interpretation of the Admati and Pfleiderer results, "by banding together, discretionary traders increase the liquidity of the market and thereby reduce the losses they suffer." (O'Hara (1994), p. 136).

The results of Admati and Pfleiderer (1988) suggest that, by banding together, discretionary traders can reduce their losses to informed traders. However, coordinating orders across discretionary traders would appear an impossible task. The one exception is at the daily opening, when pre-opening accumulated orders are batched together. Monaco (1996) extends Kyle (1985) and Admati and Pfleiderer (1988) by modeling multi-period trading with a trading mechanism that alternates between a single-price call auction and continuous trading. Monaco finds that when discretionary traders are introduced, they all choose to trade in the single price auction.

The empirical investigation of simple trading strategies to lower transaction costs is just beginning (see Blume and Goldstein (1992), Biais, Hillion, and Spatt (1995), Handa and Schwartz (1996), Harris (1994), and Harris and Hasbrouck (1996)). Harris (1994) examines the cost advantage of submitting limit orders over market orders during the trading day. Harris looks at two polar classes of traders, precommitted and passive, and finds liquidity traders benefit from using limit orders for their trades. Harris and Hasbrouck (1996) examine actual submissions of limit and market orders using the NYSE TORQ (Trades, Orders, Reports, and Quotes) database and find that limit order strategies achieve better performance than market orders.

All previous empirical studies focus on market and limit order strategies in a continuous market. We contribute to the literature by extending trading strategies to a call market. Our investigation is unique in that it includes the market-atopen order as an alternative strategy and extends the empirical work of Harris and Hasbrouck (1996) by contrasting not only submission strategies but also a call market and a continuous market. Using high frequency transaction data, we also test the empirical implications of Monaco (1996).

Specifically, we test the notion that a discretionary liquidity trader can benefit by strategically timing purchases and sales of shares. A liquidity trader, by definition, has no private information about stock price movements but trades to rebalance a portfolio. The act of trading is costly but the cost varies based on the presence of other agents in the market who are willing to trade at the time the liquidity trader submits an order. The liquidity trader does not have information about future price movements of a stock, but the trader is knowledgeable about general trading patterns and transaction costs associated with these patterns. Our 
liquidity trader is discretionary in that the trader controls both the timing and type of order submissions.

We use tick-by-tick transaction data and simulate execution prices for the market-at-open order, intraday market orders, and intraday limit orders. We find that the market-at-open order consistently produces better prices than the market and limit orders executed during the trading day, regardless of whether the orders are to buy or sell. Avoiding the continuous market provides a small liquidity trader, on average, the best price of the day. In addition, trading costs in continuous markets are so high that it is better for a small liquidity trader to wait until the following day's opening batch rather than submit a limit or market order to trade today.

The rest of paper is organized as follows: The next section describes the data, sample, and trading strategies. Section III outlines the simulation procedure. Section IV discusses the results. The last section presents a short summary and conclusion.

\section{Data, Sample, and Trading Strategies}

The study utilizes the intraday transaction data on the 1992 NYSE and AMEX Trades and Quotes Transaction File prepared by the Institute for the Study of Security Markets (ISSM). The tick-by-tick intraday database is the raw material of this study. Intraday data from the ISSM tape include time stamped transactions, bid quotes, and ask quotes. In addition, the database contains the price and size of each transaction, the support for a quote, opening prices, and closing prices. The quotes are the best bid or offer prices available. We use intraday data to classify trades (buy or sell), determine trade size, measure bid-ask spreads, and identify standing bid and ask quotes for order execution simulation.

A random sample of 417 firms is constructed by taking every fifth firm in the ticker list of the 1992 ISSM tapes, which constitute the population of 2,088 firms traded on the NYSE. Firms that were merged, taken over, delisted, or added to the exchange during the year 1992 are removed from the sample. In order to obtain firm characteristics, we require that firms be listed on the CRSP database. We further require that firms experience at least one trade each day and at least one ask and one bid quote posted prior to 10:00 a.m. so that we can simulate order executions. Firms that do not meet any one of these requirements are dropped from the sample. This data screening procedure reduces the original sample to 300 firms, which includes over 12 million trades in the year 1992.

We consider three basic strategies a precommitted liquidity trader can choose when submitting an order. First, a trader can elect to submit a market-at-open order to trade at the opening and receive the price for the opening batch. Second, a trader can elect to submit an intraday market order for immediate execution. An intraday market order executes at the standing bid (ask) quote for a market sale (purchase). Third, a trader can elect to submit a limit order that stipulates a price for the transaction. The limit order can only be filled at the stipulated price (or better) but its execution is not guaranteed. If the stock price moves away from the limit price, the limit order may not execute. Therefore, a trader is uncertain whether the limit order will be filled. We use these three types of orders to test which order 
strategy, if any, consistently outperforms the other strategies. Strategies for buying and selling are tested separately.

Recent studies concentrate only on the intraday continuous market but do not examine prices available at the opening (see Blume and Goldstein (1992), Biais, Hillion and Spatt (1995), Handa and Schwartz (1996), Harris (1994), and Harris and Hasbrouck (1996)). Our investigation is unique because we add the market-at-open order as an alternative trading strategy for a small liquidity trader.

\section{Simulation}

We simulate executions of three types of order submissions (one market-atopen order, three intraday market orders, and three intraday limit orders). The simulated trade size is one round lot, typically 100 shares. We choose the small volume order to minimize the impact of the endogenous nature of trading prices and the exogenous nature of simulated trades. We explicitly assume that simulated trades have no impact on price movements or subsequent simulated executions. The assumption of no price impact from the simulated executions is further examined in Section IV.

To allow a small liquidity trader to form a cost-effective trading strategy, we assume that the trader has an ex ante set of information about the trading patterns of firms' stocks. We partition the data into two parts: the first and the second half of 1992. The first half of 1992 is used as a learning period during which the liquidity trader builds an information set of trading patterns such as the average daily number of trades and the average size of the opening batch of an individual firm. Given the set of information, the small liquidity trader executes trading strategies over the second half of 1992.

Table 1 provides a summary of trading activities for firms in our sample during the first half of 1992. The following firm characteristics are reported in the table: firm's asset size (millions of dollars), average daily number of trades, and average size of opening batch (round lots). We report the mean, the median, the standard deviation, and the first and third quartiles of each measure. We partition the sample into the top, middle, and bottom thirds, based on the asset size and average daily number of trades. We also partition the sample according to the average size of the opening batch. In each subsample, the average bid-ask spread (cents per share) and the number of firms are reported in the table. A small liquidity trader can potentially utilize the information from Table 1 to select a winning trading strategy.

Seven trading strategies examined in this study consist of the market-at-open order, three market orders, and three limit orders. The first strategy is to submit the market-at-open order. This order is filled with the first trade of the day, and corresponds to the opening price. ${ }^{1}$ The advantages of this strategy are that it is simple, does not require any monitoring costs, and results in a guaranteed execution. The second strategy is to submit market orders. In our simulation, we submit a market

\footnotetext{
${ }^{1}$ Only those stocks with accumulated pre-opening orders open with a batch trade (call market). In our sample, $99.85 \%$ of all firm days open with a batch trade, which is denoted by the condition code " $O$ " on the ISSM data tape. The remaining firm days $(0.15 \%$ of the sample) do not open with a batch trade. In these cases, the market-at-open buy (sell) order is filled at the opening ask (bid) quote.
} 
TABLE 1

Characteristics of the Sample Firms

\begin{tabular}{|c|c|c|c|c|c|c|c|}
\hline & Mean & St. Dev. & Q1 & Median & Q3 & $\begin{array}{l}\text { Average } \\
\text { Spread }\end{array}$ & $\begin{array}{c}\text { Number of } \\
\text { Firms }\end{array}$ \\
\hline \multicolumn{8}{|c|}{ Panel A. Average Asset Size (Millions of Dollars) } \\
\hline $\begin{array}{l}\text { Lowest Third } \\
\text { Middle Third } \\
\text { Highest Third } \\
\text { Full Sample }\end{array}$ & $\begin{array}{r}636 \\
2,339 \\
14,475 \\
5,817\end{array}$ & $\begin{array}{r}336 \\
824 \\
18,429 \\
12,280\end{array}$ & $\begin{array}{r}337 \\
1,555 \\
5,714 \\
965\end{array}$ & $\begin{array}{r}563 \\
2,162 \\
8,939 \\
2,162\end{array}$ & $\begin{array}{r}965 \\
3,131 \\
16,857 \\
5,714\end{array}$ & $\begin{array}{l}28.8 \\
27.6 \\
25.3 \\
27.2\end{array}$ & $\begin{array}{l}100 \\
100 \\
100 \\
300\end{array}$ \\
\hline \multicolumn{8}{|c|}{ Panel B. Average Daily Number of Trades } \\
\hline $\begin{array}{l}\text { Lowest Third } \\
\text { Middle Third } \\
\text { Highest Third } \\
\text { Full Sample }\end{array}$ & $\begin{array}{r}36 \\
98 \\
369 \\
168\end{array}$ & $\begin{array}{r}15 \\
24 \\
352 \\
251\end{array}$ & $\begin{array}{r}22 \\
77 \\
189 \\
51\end{array}$ & $\begin{array}{r}34 \\
94 \\
254 \\
95\end{array}$ & $\begin{array}{r}51 \\
119 \\
424 \\
191\end{array}$ & $\begin{array}{l}28.3 \\
28.2 \\
25.2 \\
27.2\end{array}$ & $\begin{array}{l}100 \\
100 \\
100 \\
300\end{array}$ \\
\hline \multicolumn{8}{|c|}{ Panel C. Average Size of Opening Batches (Round Lots) } \\
\hline $\begin{array}{l}1-10 \text { Round Lots } \\
10-50 \text { Round Lots } \\
50+\text { Round Lots } \\
\text { Full Sample }\end{array}$ & $\begin{array}{r}7.2 \\
27.5 \\
156.3 \\
82.8\end{array}$ & $\begin{array}{r}1.8 \\
11.1 \\
139.1 \\
112.7\end{array}$ & $\begin{array}{r}5.7 \\
18.5 \\
74.3 \\
22.5 \\
\end{array}$ & $\begin{array}{r}7.6 \\
25.6 \\
111.0 \\
43.3\end{array}$ & $\begin{array}{r}8.6 \\
49.4 \\
187.7 \\
95.3\end{array}$ & $\begin{array}{l}30.7 \\
28.1 \\
25.8 \\
27.2\end{array}$ & $\begin{array}{r}15 \\
153 \\
132 \\
300\end{array}$ \\
\hline
\end{tabular}

This table presents firm characteristics and trading patterns for the sample. Panels $A-C$ report measures of firm asset size, average daily number of trades, and average size of opening batches. The mean, standard deviation (St. Dev.), first quartile (Q1), median, and third quartile (Q3) of each measure are reported. In addition, the sample is partitioned based on each above measure to further inform a small liquidity trader. The average bid-ask spread (in cents) and the frequency distribution of firms are reported for each subsample.

order at 10:00 a.m., 12:00 noon, and 2:00 p.m. All market orders are filled at the best bid or offer at the time of submission: the lowest ask for a buy, the highest bid for a sale. ${ }^{2}$ The advantage of this strategy is that it results in an immediate execution at the best currently available price.

The third strategy is to submit limit orders. Simulated limit orders are conditioned on current quotes, with a limit price one tick ( 12.5 cents) below the current ask for sell limit orders and one tick above the current bid for buy limit orders. In addition, we require that a limit order be executed by or at 3:30 p.m. or it is withdrawn and replaced with a market order. This feature reflects that the trader is precommitted to trading (Harris (1994)) and requires all trades to execute "today" in all strategies. ${ }^{3}$ The buy limit orders are executed only when a subsequent trade after submission is executed at the requested or lower price. A similar setup is used for the sell limit orders. ${ }^{4}$ We hold to the rule (Rule 71) that intra-spread limit

\footnotetext{
${ }^{2}$ Filling orders at the standing quotes is a feature of the simulation and not the case for all market orders on exchanges. Market orders are guaranteed at least the current ask or bid price but can be "worked" by a specialist for a more favorable price. We ignore this practice in our evaluation of trading strategies but address its potential impact in Section IV.

${ }^{3}$ An alternative strategy is to use a market-at-close order for the limit orders that are not executed during the trading day. This strategy produces quantitatively similar results to replacing unexecuted limit orders with market orders at 3:30 p.m.

${ }^{4}$ Execution of limit orders is inferred if a transaction occurs at the same or better than the limit price. This procedure may overstate the execution frequency of limit orders because it puts the simulated limit order before potential hidden limit orders. However, this procedure provides an advantage to the simulated limit orders and makes cost savings over limit orders conservative. Any restriction on
} 
orders cannot be traded through. Thus, a trade executed at a lower (higher) price than our buy (sell) limit price signals that our limit order would have been filled first at our requested price. Intraday limit orders are submitted daily at 10:00 a.m., 12:00 noon, and 2:00 p.m. (NYSE clock time). The limit order strategies produce better prices than the market order prices if the limit orders are filled. However, the execution of a limit order depends on changes in the bid and ask quotes, subsequent trades, and future stock price movements. The disadvantages of this strategy involve monitoring costs, including costs of obtaining current bid-ask quotes to formulate a limit price, and costs of switching the limit order to a market order if the limit order fails to execute before the specified time.

Using the actual intraday transaction prices from the ISSM database, we program a simulation routine to generate execution prices for each of the seven strategies (the market-at-open order, three market orders, and three limit orders). For each trading day in the second half of 1992, and for each of the 300 firms in the sample, seven order execution prices are obtained. These execution prices are recorded and sorted. We define cost savings attributable to using the market-atopen orders instead of intraday market and limit orders. The cost savings for a buy strategy are defined as the simulated purchase price under the buy strategy minus the opening price. The cost savings for a sell strategy are defined as the opening price less the sale price under the sell strategy. So defined, positive (negative) cost savings measure the advantage (disadvantage) of the market-at-open order strategy over the intraday limit or market order strategies. The cost savings are presented on a cents per share basis.

The rest of analysis in the paper uses the cost savings of the market-at-open order over each of three market orders and three limit orders. For each of six sequences of cost savings, let $S_{i t}$ denote the cost savings of firm $i$ on day $t$, where $i=1, \ldots, N$, the total number of firms, and $t=1, \ldots, T$, the number of trading days in the second half of 1992. We first compute the average cost savings on day $t$ over all firms,

$$
S_{\bullet t}=\sum_{i=1}^{N} S_{i t} / N .
$$

Next, assuming independence in daily average cost savings across $T$ trading days, we compute a $t$-statistic,

$$
t=\frac{\sum_{t=1}^{T} S_{\bullet t} / T-0}{\text { st. err. }\left(S_{\bullet t}\right)} .
$$

We use the above $t$-statistic to measure statistical significance of cost savings by using the market-at-open orders instead of intraday market or limit orders. We present the full sample results first. Then, we present results in partitioned samples. Next, we summarize simulation issues. Finally, we discuss other types of limit order strategies.

simulated limit order execution would moderate the limit order performance and make our results even stronger. 


\section{Results}

\section{A. Full Sample Results}

Table 2 contains descriptive statistics on the cost savings attributable to using the market-at-open orders instead of intraday market and limit orders for the full sample. We separately report cost savings for buy and sell strategies. In addition to the mean and the standard deviation, we also tabulate a set of percentiles to help describe the distribution of the cost savings.

TABLE 2

Cost Savings of Market-at-Open Order over Intraday Market and Limit Orders: Full Sample Results

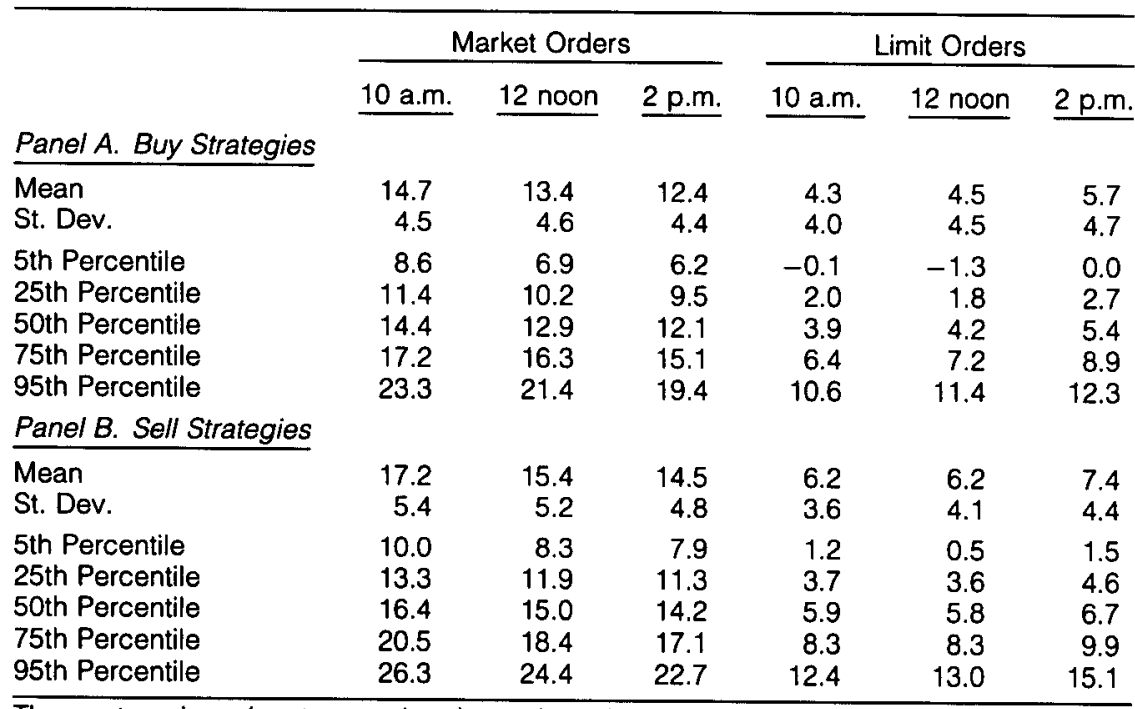

The cost savings (cents per share) are the advantages of using market-at-open orders instead of intraday market or limit orders. The cost savings for a buy strategy are defined as the simulated purchase price under the buy strategy minus the opening price. The cost savings for a sell strategy are defined as the opening price less the sale price under the sell strategy. The mean, standard deviation (St. Dev.), and a set of percentiles are reported for each of three market order strategies and each of three limit order strategies. All means are statistically significant at the 0.001 significance level.

Table 2 summarizes the performance of each of the market and limit order submission strategies. The average cost savings of the market-at-open order are 12.4 to 17.2 cents per share over the three market order strategies, and 4.3 to 7.4 cents per share over the three limit order strategies. ${ }^{5}$ Statistical tests reveal that all average cost savings are significantly greater than zero at the 0.001 level. Probably more importantly, cost savings of 4 to 17 cents per share appear to be economically significant to a small liquidity trader. Further, by examining the distributions of the

\footnotetext{
${ }^{5}$ Harris and Hasbrouck (1996) find trading with limit orders is best when the spread is two or more ticks (25+ cents) and the limit price is set at one tick inside the spread. When spreads are one tick, they argue that the best strategy is to submit buy limit or sell limit orders at the market. We provide a test of this more sophisticated strategy at the end of this section.
} 
cost savings, we find that the 25th percentiles of the cost savings for buy and sell strategies are also greater than zero. Statistics in Table 2 suggest that not only does the market-at-open order beat the intraday market and limit orders by the mean, it also outperforms them more than $75 \%$ of the time. Therefore, the clear winner is the market-at-open trading strategy. A discretionary liquidity trader avoids the cost of the continuous market by executing trades at the opening and, on average, receives better prices regardless of whether the order is to buy or sell.

The cost savings in Table 2 also indicate that, on average, limit orders receive better prices than market orders. Across different trading strategies, the market order strategies are clearly the worst strategies. On average, they lag the marketat-open strategy by at least a 12-cent margin. The performance of the limit order strategies is much closer to that of the market-at-open order. On average, the limit order prices are around five cents worse than the opening price. Interestingly, the later in the day a limit order is submitted, the worse its execution price. It appears that intraday liquidity decreases monotonically over time in a continuous market. This result is consistent with the liquidity implications of Kyle (1985) and Monaco (1996).

We also compute the proportion of limit order executions and compare our results to those from Harris and Hasbrouck (1996). In our simulation, when limit orders are submitted one tick inside the bid ask quotes at 10:00 a.m., the resulting execution rates are $86 \%$ for buy limit orders and $85 \%$ for sell limit orders. Harris and Hasbrouck (1996) use the TORQ database and provide estimates of execution percentages for small volume transactions from actual orders. They claim that limit orders of 200 shares or less, submitted when spreads are two ticks, are executed $89.4 \%$ of the time for sell orders and $87.7 \%$ of the time for buy orders. When we compare the execution rates between their study and our simulation, we find that our simulated limit order executions closely resemble actual order submissions. This result provides some assurance that our simulation fairly represents actual trading patterns.

The overall results from Table 2 indicate that, on average, the market-atopen order strategy consistently outperforms the market and limit order strategies. However, under what kind of trading patterns are the cost savings greatest? Additionally, are there predictable situations where the market-at-open order strategy does not work well?

\section{B. Cost Savings Conditioned on Asset Size, Trading Activity, and Opening Batch Size}

We test firm characteristics (asset size, daily number of transactions, opening batch size) from the first half of 1992 against the cost savings in the second half of 1992 . Our goal is to identify a winning strategy that consistently produces the greatest cost advantage. We partition the full data sample into three subsamples based on each of the three measures reported in Table 1. Panels A-C in Table 1 outline three sets of subsamples. The sample partitioning is important for two reasons. First, given an ex ante set of information about the firms, a small liquidity trader may be able to design a cost-effective trading strategy of alternating between submission choices conditioned on characteristics of the firm. Second, 
the partitioned sample results may reveal relationships between the magnitude of cost savings and trading patterns of individual stocks.

We partition the sample into three asset size categories. Panel A in Table 3 reports average cost savings of the market-at-open order over the market and limit order strategies for each of the three asset size categories. For all buy and sell market orders, average cost savings always stay more than 12 cents across all asset categories. For the limit orders, average cost savings vary between 3.1 and 8.8 cents for buy and sell limit orders. We find that the smaller the firm, the greater the advantage to the market-at-open order. As the asset size of the firm increases, in general, trading activity tends to increase. Intensified trading tends to reduce bid-ask spreads and increase the frequency of limit order executions, thus decreasing the cost savings of the market-at-open order strategy.

TABLE 3

Average Cost Savings of Market-at-Open Order over Intraday Market and Limit Orders: Partitioned Sample Results

\begin{tabular}{|c|c|c|c|c|c|c|}
\hline \multirow[b]{3}{*}{ Panel A. By Asset Si } & \multicolumn{3}{|c|}{ Market Orders } & \multicolumn{3}{|c|}{ Limit Orders } \\
\hline & 10 a.m. & 12 noon & 2 p.m. & 10 a.m. & 12 noon & 2 p.m. \\
\hline & & & & & & \\
\hline $\begin{array}{l}\text { Lowest Third } \\
\text { Middle Third } \\
\text { Highest Third }\end{array}$ & $\begin{array}{l}17.7 \\
16.2 \\
14.0\end{array}$ & $\begin{array}{l}15.8 \\
14.6 \\
12.7\end{array}$ & $\begin{array}{l}14.5 \\
13.8 \\
12.2\end{array}$ & $\begin{array}{l}7.0 \\
5.3 \\
3.4\end{array}$ & $\begin{array}{l}7.4 \\
5.5 \\
3.1\end{array}$ & $\begin{array}{l}8.8 \\
6.7 \\
4.2\end{array}$ \\
\hline \multicolumn{7}{|c|}{ Panel B. By Number of Trades } \\
\hline $\begin{array}{l}\text { Lowest Third } \\
\text { Middle Third } \\
\text { Highest Third }\end{array}$ & $\begin{array}{l}17.4 \\
16.9 \\
13.6\end{array}$ & $\begin{array}{l}15.9 \\
15.0 \\
12.3\end{array}$ & $\begin{array}{l}14.5 \\
14.0 \\
11.9\end{array}$ & $\begin{array}{l}7.4 \\
5.1 \\
3.3\end{array}$ & $\begin{array}{l}8.0 \\
5.2 \\
2.8\end{array}$ & $\begin{array}{l}9.6 \\
6.4 \\
3.7\end{array}$ \\
\hline \multicolumn{7}{|c|}{ Panel C. By Size of Opening Batch } \\
\hline $\begin{array}{l}\text { 1-10 Round Lots } \\
10-50 \text { Round Lots } \\
50+\text { Round Lots }\end{array}$ & $\begin{array}{l}18.9 \\
17.2 \\
14.2\end{array}$ & $\begin{array}{l}17.0 \\
15.4 \\
12.9\end{array}$ & $\begin{array}{l}15.6 \\
14.2 \\
12.3\end{array}$ & $\begin{array}{l}8.3 \\
6.2 \\
3.8\end{array}$ & $\begin{array}{l}9.2 \\
6.6 \\
3.4\end{array}$ & $\begin{array}{r}11.2 \\
8.0 \\
4.3\end{array}$ \\
\hline Full Sample & 16.0 & 14.4 & 13.5 & 5.2 & 5.4 & 6.5 \\
\hline
\end{tabular}

The overall full sample averages of cost savings (cents per share) reported in Table 2 are partitioned by firm asset size, average daily number of trades, and average size of the opening batches. Results are documented in Panels A-C, respectively. The partitions are performed based on the subsamples listed in Table 1. All means of the cost savings are statistically significant at the 0.001 significance level.

Next we partition the data into three subsamples based on the average daily number of trades in the first half of 1992. Panel B in Table 3 presents the average cost savings across the three trading intensity categories. In all cases, both market orders and limit orders still fall behind the market-at-open order. For market orders, the differences are at least 11 cents. For limit orders, the average cost savings are between 2.8 and 9.6 cents. The average cost savings are negatively correlated with the average daily number of transactions. As the average daily number of transactions increases, the market and limit order strategies improve execution prices. In the most actively traded stock category, average cost savings of marketat-open orders are between 2.8 and 3.7 cents over limit orders. In the least actively traded stock category, the average cost savings are between 7.4 and 9.6 cents more 
than limit orders. These results are consistent with the liquidity explanations by Kyle (1985) and Monaco (1996). Larger firms with greater trading activity provide higher execution percentages for limit orders and, therefore, a higher percentage of trades inside the posted bid-ask quotes. The results are also consistent with Huang and Stoll (1996), who report that less actively traded stocks have higher execution costs than more actively traded stocks.

Finally, we examine the effect of opening batch size on cost savings. The size of an opening batch is particularly important. First, it is a measure of trading activity at the opening. Second, it is closely related to our simulation procedures. Once again, we form three subsamples. The subsamples are constructed based on the average opening batch size of each firm over the first half of 1992. The three categories include firms with average opening batch sizes in the following three ranges: $1-10$ round lots (15 firms), $10-50$ round lots (153 firms), and more than 50 round lots (132 firms).

Panel $\mathrm{C}$ in Table 3 summarizes the results partitioned by average opening batch size. Since an opening batch size is also a measure of trading intensity, we expect that these partitioned results are correlated with the results partitioned by number of trades (see Panel B in Table 3). Results in Panel C of Table 3 confirm our expectation. As an opening batch size increases, average cost savings decrease. The differences in average cost savings between firms with small opening batches and firms with large opening batches vary between 3.3 and 6.9 cents. However, even for firms with the largest average opening batch sizes, average cost savings are at least 12.3 cents per share more than market orders and between 3.8 and 4.3 cents per share over limit orders. The cost savings are statistically significant at the 0.001 level and appear economically significant to a small liquidity investor.

\section{Simulation Issues}

Simulations do have inherent problems, and this simulation is not an exception. This study is conditioned on the premise that a hypothetical 100-share market, limit, or market-at-open order does not change the price path of the security at or following the hypothetical execution. For market orders, we assume that we can fill a small volume market order at the posted standing quotes when the order is submitted. For limit orders, we assume that we can fill a small volume limit order only when there is a transaction price no worse than the limit price after the order submission. Under these assumptions, the simulated market and limit order prices can be viewed as realized prices and they are affected little by the nature of our research procedure. However, a similar statement cannot be as easily made for the simulated market-at-open order prices. This issue is particularly sensitive if the size of the opening batch is small.

The cost savings reported in Tables 2 and 3 are computed under the assumption that the opening price does not change with an additional small order of 100 shares. However, an increase in the number of shares traded at the opening could change the opening price and, therefore, work against the results presented in this study. The likelihood of a potential price impact differs by the sizes of opening batch. For trading days with large opening batches, an additional one round lot of shares at the opening should have a minimal impact on the opening price. For trading days with 
small opening batches, a small additional order could be significant and change the opening price. To measure the sensitivity of the cost savings with respect to the assumption of no price impact on the opening price, we design the following experiment. For any firm in our sample, regardless of its average opening batch size, we penalize the market-at-open order price by one tick (reducing the cost savings by one tick) on all trading days when the firm opens with no more than 10 round lots of shares. If a firm opens with more than 10 round lots of shares, no penalty is imposed to the market-at-open execution price on that day. The one-tick penalty is a severe handicap to the market-at-open order strategy for two reasons. First, the procedure assumes that if the opening batch is small, then the opening price always changes with an additional 100-share order: the opening price moves up one tick if the order is a purchase; and down one tick if it is a sale. In reality, the opening price may not always respond to an additional small order even when the pre-open accumulated order quantity is small. Second, the size of the price movement is set at one tick ( 12.5 cents). Consider the average bid-ask spreads reported in Table 1. A one-tick penalty on each side of the trade (buy or sell) covers 25 cents, which is nearly the average size of the bid-ask spread.

Table 4 documents the average cost savings with the one-tick penalty to the market-at-open order strategy. We further partition the sample based on the average size of the opening batch so that the results in Table 4 are directly comparable to those of Panel $\mathrm{C}$ in Table 3. Additionally, we report the frequencies of the penalty being triggered within each subsample. Comparing the results in Table 4 and Table 3 , we find that the average cost savings in the full sample decrease by 2.4 cents. About $19 \%$ of all firm trading days open with 10 round lots or less. For market orders, average cost savings to the market-at-open order fall to between 11.1 and 13.5 cents per share. For the limit orders, average cost savings vary between 2.8 and 4.1 cents per share. For firms with large opening batches (average more than 50 round lots), the one-tick penalty makes little difference $(0.5$ cents $)$ in the average cost savings. The reason is that these firms rarely have small opening batches (only $4 \%$ of the time). In the median opening size firm category (average opening batch size between 10 and 50 round lots), there is a reduction of 3.5 cents in the average cost savings. However, the market-at-open strategy is still superior to intraday order submissions. Small opening batches make up $28 \%$ of all trades in this category. Average cost savings are at least 10.7 cents per share over market orders and at least 2.7 cents per share over limit orders. For firms with small opening batches (average 10 round lot or less), the one-tick penalty dramatically changes the average cost savings by eight cents across the board. Around 64\% of the market-at-open orders in this category are no more than 10 round lots, and thus subject to the one-tick penalty. In this category, average costs savings are 7.5 cents per share or more than market orders and 0.2 cents per share or more than limit orders.

With the penalty feature, the average cost savings over the 10:00 a.m. limit order with $1-10$ round lots opening size is 0.2 cents per share. The mean cost savings is insignificantly different from zero, indicating that, on average, the market-atopen order breaks even with the 10:00 a.m. limit order when the opening batch size is small. Even though the market-at-open order generates statistically significant cost savings over all other strategies, the results in the small opening batch subsam- 
TABLE 4

Average Cost Savings: With Penalty for Small Open Sizes

\begin{tabular}{|c|c|c|c|c|c|c|c|}
\hline & \multicolumn{3}{|c|}{ Market Orders } & \multicolumn{3}{|c|}{ Limit Orders } & \multirow{2}{*}{$\begin{array}{c}\text { Percent } \\
\text { Penalized }\end{array}$} \\
\hline & 10 a.m. & 12 noon & 2 p.m. & 10 a.m. & 12 noon & 2 p.m. & \\
\hline $\begin{array}{l}\text { 1-10 Round Lots } \\
10-50 \text { Round Lots } \\
50+\text { Round Lots }\end{array}$ & $\begin{array}{l}10.9 \\
13.6 \\
13.7\end{array}$ & $\begin{array}{r}9.0 \\
11.8 \\
12.4\end{array}$ & $\begin{array}{r}7.5 \\
10.7 \\
11.9\end{array}$ & $\begin{array}{l}0.2 \\
2.7 \\
3.3\end{array}$ & $\begin{array}{l}1.2 \\
3.1 \\
2.9\end{array}$ & $\begin{array}{l}3.1 \\
4.5 \\
3.8\end{array}$ & $\begin{array}{r}64 \% \\
28 \% \\
4 \%\end{array}$ \\
\hline Full Sample & 13.5 & 12.0 & 11.1 & 2.8 & 2.9 & 4.1 & $19 \%$ \\
\hline
\end{tabular}

The cost savings (cents per share) are reduced by one tick (12.5 cents) whenever the size of the opening batch is 10 round lots or less. The table reports average cost savings of using a market-at-open order instead of intraday market or limit orders. It also reports proportions of orders that are penalized for small opening batches. Results are further partitioned by average size of the opening batches. All means of the cost savings except the mean for the 10 a.m. limit order with 1-10 round lot opening size are statistically significant at the 0.01 level.

ple suggest that a small liquidity trader should not blindly apply the market-at-open order strategy to all firms. Caution should be exercised when selecting a strategy to trade stocks of firms with small opening batches.

Trading at the opening may entail inherent additional risk. Stoll and Whaley (1990) document that the variance in returns measured from opening prices is about $12 \%$ higher than that measured from closing prices. This implies that a liquidity trader faces more price risk trading at the opening than trading in the continuous market. However, in our simulations, standard deviations of simulated execution prices are quantitatively the same across all seven strategies. ${ }^{6}$ Therefore, the potential additional risk reported by Stoll and Whaley (1990) may not translate into additional costs to liquidity traders.

Our study is also closely related to another result from Stoll and Whaley (1990). They find that the proportion of trades at the opening is negatively correlated with the size of the firm. Therefore, smaller firms have a greater reduction in liquidity following the opening. The results are consistent with our simulated executions because cost savings for market-at-open orders are highest for the subsample of firms with the smallest asset values and the lowest trading activity. In addition, limit orders are filled less frequently for smaller firms.

Another potential problem of this simulation is the practice of working market orders. Angel (1994) documents that market orders receive approximately a fourcent per share price improvement over standing quotes. In our simulations, the structure of executing market orders does not allow for a specialist to work a market order. To estimate the potential impact of working market orders, we apply Angel's results to our data. Angel finds that price improvements occur about $28 \%$ of the time for market orders, usually with a magnitude of one tick ( 12.5 cents). When the spread is one tick, price improvement occurs only about $10 \%$ of the time. When the spread is two ticks, price improvement occurs about $50 \%$ of the time. We apply these frequencies to our sample. In our sample, spreads are one tick about $35 \%$ of

\footnotetext{
${ }^{6}$ We measure the standard deviations of the opening prices and the intraday market or limit order prices. Standard parametric $t$-tests indicate that the mean standard deviation of the opening prices is (statistically insignificantly) smaller than those of the intraday market and limit order prices.
} 
the time, and two ticks or greater $65 \%$ of the time. Using a price improvement of one tick, the average price improvement is five cents per share. However, because opening prices are, on average, 12 to 17 cents better than market order prices (see Table 2), the market-at-open strategy still beats the intraday market order strategies by at least seven cents per share.

Angel (1994) also points out that limit orders receive substantially less price improvement than market orders. Our simulation practice of replacing unexecuted limit orders with market orders at 3:30 p.m. would suggest that these replaced orders could receive price improvement. However, Angel claims that market orders later in the day do not receive price improvement as frequently as in the morning. Angel finds that market orders at 3:30 p.m. receive price improvement only $25 \%$ of the time. Therefore, the replaced limit orders, which reflect $15 \%$ of all 10:00 a.m. limit orders, would net a price improvement $25 \%$ of the time and change the average execution price by less than one-half cent $(0.15 \times 0.25 \times 12.5$ cents $=0.47$ cents). This adjustment is insufficient to change any of the results presented in the previous sections.

Finally, it is important to note that no implicit monitoring costs have been assigned to the limit order strategy. Clearly the limit order strategy requires a knowledge of current quotes and a monitoring cost for withdrawal and replacement at 3:30 p.m. Harris (1994) assigns an implicit cost of two cents per share for each limit order submission strategy. We do not add the implicit cost for monitoring the limit order strategies, thus presenting our results in a conservative setting. Adding an implicit cost to the limit order strategies simply increases the cost savings to the market-at-open orders and makes our results even stronger.

\section{Other Types of Limit Orders Strategies}

Our limit order strategies are simple but may not be the best performing strategies given the results of Harris and Hasbrouck (1996). They find that limit order strategies conditioned on the current quote are optimal. When the spread is one tick, limit orders should be submitted at the current quote (buy limit order at the current highest bid, sell limit order at the current lowest ask). We test our results against this more sophisticated limit order strategy. We implement the procedure suggested by Harris and Hasbrouck by submitting limit orders inside the spread when the spread is at least two ticks, and submitting a limit order at market when the spread is one tick. We violate Rule 72 (time preference for orders) by moving our limit order to the front of the queue for execution. For our sample, spreads of one tick occur $35 \%$ of the time. This more sophisticated limit order strategy still fails to beat the average opening price. For buy limit orders, the average cost savings using the market-at-open strategy are still at least 2.5 cents. If we were to place the limit order in its proper place in the queue, we would only increase the average purchase price of the limit orders. ${ }^{7}$ Similar results are obtained with sell limit orders.

\footnotetext{
${ }^{7}$ The ISSM database does not consistently update the depth of a standing quote when an additional limit order arrives at the best quote. Therefore, the actual depth of a quote at the time of our limit order submission cannot be determined. Violation of Rule 72 provides the most favorable advantage to the limit order strategy in this test.
} 
We also test a strategy that the trader submits limit orders conditioned on the size of the spread. Limit orders are submitted when the spread is at least two ticks ( 25 cents), three ticks ( 37.5 cents), and four ticks ( 50 cents). Table 5 presents results across the three different minimum spreads. We report the cost savings of the opening prices over the limit order prices, along with frequencies of limit order executions.

TABLE 5

Average Cost Savings over Limit Orders: Trading Strategies Conditioned on Size of Bid-Ask Spread (Execution Percentage of Limit Orders)

\begin{tabular}{lccc}
\hline Size of the Spread & 10 a.m. & $\frac{12 \text { noon }}{2}$ & $\frac{2 \text { p.m. }}{6.2}$ \\
\cline { 2 - 4 } 12.5 cents & 5.2 & 5.4 & 6.5 \\
& $(86 \%)$ & $(78 \%)$ & $(66 \%)$ \\
25 cents & 6.8 & 7.5 & 8.9 \\
& $(74 \%)$ & $(69 \%)$ & $(56 \%)$ \\
37.5 cents & 8.7 & 9.4 & 10.6 \\
& $(59 \%)$ & $(49 \%)$ & $(35 \%)$ \\
50 cents & 9.8 & 10.6 & 11.4 \\
& $(35 \%)$ & $(25 \%)$ & $(16 \%)$ \\
\hline
\end{tabular}

Limit orders are submitted when the bid-ask spreads are at least 12.5 cents (one tick), 25 cents (two ticks), 37.5 cents (three ticks), and 50 cents (four ticks). This table reports the average cost savings (cents per share) of the market-at-open order strategy over each of the limit order strategies. Percentages of limit order executions are reported in brackets. All means of the cost savings are statistically significant at the 0.001 significance level.

The cost savings in Table 5 are consistent with the results in Table 2. The average opening price is the best price regardless of whether the order is to buy or sell. When the spreads are only one tick, a buy limit order (one tick above the bid) is the same as a market order because the limit price matches the standing ask quote. Waiting for spreads to increase to at least two ticks produces inferior average limit order execution prices. The average cost savings of the marketat-open order increase by at least 1.6 cents. Furthermore, if a trader waits for even larger spreads (three or four ticks), the frequencies of limit order executions dramatically decrease. At 3:30 p.m., the unexecuted limit orders are replaced by market orders which receive unfavorable prices.

For our simulations, the frequency of trades executed inside the spread falls as a trader waits for larger spreads. For three-tick spreads, limit orders execute only $59 \%$ of the time for even the earliest 10:00 a.m. submission time. Therefore, $41 \%$ of the simulated limit orders are withdrawn and replaced by market orders for execution at 3:30 p.m. When the spreads are four ticks (50 cents), limit order executions fall to less than $40 \%$ of submissions and replacement market orders increase to more than $60 \%$. The increase in replacement orders offsets any gains from waiting for spreads to widen.

In the simulations thus far, the market-at-open strategy is the clear winner, but what if a liquidity trader decides to rebalance a portfolio while the market is open? Is it better to wait one day and get the next day's opening price or submit a limit order today? We answer this question by comparing the next day's opening price with today's transaction prices for market and limit orders. On average, the 
opening price a day later is still a better trading price. By waiting one day when buying a share, the trader gives up 1.1 cents from the prior day's opening price. By waiting one day to sell a share, the 1.1-cent difference is a gain to the trader.

Other modifications for more sophisticated limit order strategies could be cost effective. The recent direction of a trade (market-initiated buy or market-initiated sell) may help a liquidity trader improve limit order prices. Part of the bid-ask spread is usually attributed to inventory costs of the specialist (see Bagehot (1971) for the components of the bid-ask spread). A specialist may be willing to make price concessions to rebalance his portfolio. Therefore, following a sell order (an increase to the specialist's inventory), a liquidity trader submitting a buy order (a decrease in the specialist's inventory) may be able to trade at a more favorable price as the specialist rebalances inventory. One strategy is to submit a sell (buy) limit order immediately following a market buy (sale) to capture this potential temporary price concession. Results with this additional condition are quantitatively similar to results with the unconditional strategies.

\section{Summary and Conclusion}

We extend the market microstructure literature by examining trading strategies of a discretionary liquidity trader in a call market as well as a continuous market. Our investigation of trading strategies uses intraday market and limit orders and introduces the market-at-open order as an alternative strategy for a small liquidity trader. We find a small liquidity trader can significantly reduce transaction costs by trading at the opening. Using tick-by-tick transaction data, we demonstrate that the market-at-open order consistently produces better prices than market and limit orders executed during the trading day. Avoiding the bid-ask pricing convention of the continuous market is cost effective. In addition, avoiding costs of the continuous market is so favorable that even waiting an extra day to trade at the opening is cost effective for a liquidity trader. Our results match the theoretical predictions of Admati and Pfleiderer (1988) and Monaco (1996) in that by banding together, liquidity traders lower their costs. In our simulations, price improvement of limit orders over market orders is consistent with Harris (1994) and Harris and Hasbrouck (1996).

The results are also intuitively pleasing. The opening, a call market, brings together both informed buyers and sellers, and the uninformed traders can get the consensus price by just being there at the right time. For the remainder of the day, a continuous market, a liquidity trader does not know if informed buyers or sellers are present. In fact, informed buyers (sellers) should show up to trade with the liquidity trader when shares are undervalued (overvalued). Therefore, during the day, the liquidity trader is at a distinct disadvantage.

Finally, although a more sophisticated limit order strategy may eventually prove to be better than the market-at-open strategy, it is clear that the opening price is an excellent benchmark for measuring the performance of any trading strategy. First, the opening price is easy to obtain, and second, it is the same price for both buyers and sellers. 


\section{References}

Admati, A., and P. Pfleiderer. "A Theory of Intraday Patterns: Volume and Price Variability." Review of Financial Studies, 1 (Spring 1988), 3-40.

Angel, J. "Who Gets Price Improvement on the NYSE?" Working Paper, Georgetown Univ. (1994).

Bagehot, W. "The Only Game in Town." Financial Analysts Journal, 27 (1971), 12-14.

Biais, B.; P. Hillion; and C. Spatt. "An Empirical Analysis of the Limit Order Book and the Order Flow in the Paris Bourse." Journal of Finance, 50 (Dec. 1995), 1655-1689.

Blume, M. E., and M. A. Goldstein. "Differences in Execution Prices among the NYSE, the Regionals and the NASD." Working Paper, Rodney L. White Center for Financial Research, Wharton School (1992).

Handa, P., and R. Schwartz. "Limit Order Trading." Journal of Finance, 51 (Dec. 1996), 1835-1861.

Harris, L. "Optimal Dynamic Order Submission Strategies in Some Stylized Trading Problems." Working Paper, Univ. of Southem California (1994).

Harris, L., and J. Hasbrouck. "The SuperDOT Evidence on Order Submission Strategy: Market vs. Limit Orders." Journal of Financial and Quantitative Analysis, 31 (June 1996), 213-231.

Huang, R., and H. Stoll. "Dealer versus Auction Markets: A Paired Comparison of Execution Costs on NASDAQ and NYSE." Journal of Financial Economics, 41 (July 1996), 317-357.

Kyle, A. S. "Continuous Auctions and Insider Trading." Econometrica, 53 (1985), 1315-1336.

Monaco, S. "Liquidity and Information Flow in Securities Markets: The Effect of Sequential Variation in Market Structure." Working Paper, Indiana Univ. (1996).

O'Hara, M. Market Microstructure Theory. Cambridge, MA: Blackwell Publishers Inc. (1994).

Stoll, H., and R. E. Whaley. "Stock Market Structure and Volatility." Review of Financial Studies, 3 (Fall 1990), 37-70. 
Copyright of Journal of Financial \& Quantitative Analysis is the property of Journal of Financial \& Quantitative Analysis and its content may not be copied or emailed to multiple sites or posted to a listserv without the copyright holder's express written permission. However, users may print. download, or email articles for individual use. 